\title{
Problem-based learning in clinical nursing education: Integrating theory and practice
}

\author{
Anna C. Ehrenberg ${ }^{a, b, *}$, Marianne Häggblom ${ }^{a}$ \\ a Department of Health and Social Sciences, Dalarna University, SE 791-88 Falun, Sweden \\ b Department of Caring Sciences, Örebro University, Örebro, Sweden
}

Accepted 12 April 2006

KEYWORDS
Problem-based
learning;
Nursing education;
Clinical practice;
Students;
Preceptors

\section{Background}

Nursing education in Sweden has been subject to considerable changes during recent decades,

\footnotetext{
* Corresponding author. Tel.: +46 23 778472; fax: +46 23 778401.

E-mail address: aeh@du.se.
}

\begin{abstract}
Summary Over the last few decades, nursing education in Sweden has undergone many changes in its length, content, and academic level. Pedagogical developments have occurred, but not as much change has taken place in the clinical part of education. Therefore, a project was initiated to improve students' integrated learning, ability to actively search for knowledge, reflect critically, and to improve the clinical learning environment, during the clinical training part of the undergraduate nursing program at a Swedish university. This was accomplished through applying problem-based learning (PBL), supporting reflection, applying a new model for supervision, and supporting nursing preceptors. The project was carried out during clinical studies in acute care in the second year of a nursing undergraduate program.

The aim of this study was to describe nursing students' and their preceptors' experiences of problem-based learning and a new model for supervision in clinical education. A total of 45 students and 30 preceptors participated by answering a questionnaire and an interview.

The findings showed that the project overall was perceived positively by students and preceptors. The possibility for supervised reflection was perceived as positive by both students and preceptors, although it sometimes was difficult for preceptors to set aside time. Research-based knowledge was rarely used in clinical teaching. (c) 2006 Elsevier Ltd. All rights reserved.
\end{abstract}

regarding such aspects as its length, content and academic level. New approaches to teaching and learning have been implemented in theoretical aspects, but limited efforts have been directed to clinical education. Clinical education traditionally has had the character of an apprentice system mainly with non-registered nurses as preceptors and role models for the students (Grahn, 1987). 
There are still students, nurses and even lecturers who look upon the clinical part of nursing education merely as practical training in nursing procedures and routines without any connection with theoretical nursing. Theoretical knowledge is seen as 'knowing that', which is learnt by intellectual and cognitive activities. Practical knowledge is seen as 'knowing how', which is gained by experience from practical training and doing things (Benner, 1984; Schön, 1987; Craddock, 1993). Accordingly, the theoretical and practical parts of nursing education are still often separated instead of being intertwined as a whole, where practical experiences can be illuminated and critically analysed by means of theoretical knowledge and then further redefined and extended within practice. This so-called 'theory-practice gap' is reinforced by the fact that nurses to a very low extent read and apply findings from nursing research to their clinical practice (Nilsson Kajermo et al., 1998; Estabrooks, 2003; Wallin et al., 2003).

\section{Theoretical perspective}

During their clinical education students are expected to learn nursing skills and procedures and to deepen the search for knowledge, critical thinking and problem solving, as well as develop personally and professionally. This means that students' goals should include increased self-knowledge and scientific awareness in addition to their gradual improvement in professional nursing. In order to facilitate the clinical education process many different teaching and supervision models have been developed and evaluated over the last few decades (McCaugherty, 1991; Severinsson, 1998; Mallette et al., 2005). Preceptors and clinical lecturers have been found to be more or less helpful in making clinical education successful and reliable (Fitzgerald, 1994; Öhrling and Hallberg, 2000), and a need for training and support of the preceptors has also been demonstrated (Lee, 1997; Kaviani and Stillwell, 2000). Interest in learning from experience by means of reflection has grown and it has been argued that the process promotes deep learning (Schön, 1983, 1987; Williams, 2001; Murphy, 2004). Since clinical education in nursing is also a matter of preparing the students for the transition into the nursing profession and for work in the future health care system, both of which are unpredictable, the aim for clinical education must be to help the students to improve their ability to 'learn how to learn' in order to establish their capacity to handle changing realities and situations (Bowden and Marton, 1998; Baker, 2000).

\section{Problems in clinical education}

During clinical education Swedish nursing students are mostly supervised by nurses, who often lack academic training, as nursing programs were incorporated in the universities in 1993. Thus, the majority of nurses with older education have a diploma in nursing and, therefore, lack fundamental skills in nursing research. Rather often, they also lack preceptor training. This group still constitutes a large share of experienced nurses and often holds functions as clinical supervisors. Hence, the support given to the students for learning nursing from an academic perspective is insufficient. Since the preceptors themselves lack knowledge of how to find and use new knowledge gained by research, they cannot guide the students in this area. For the same reason, they have difficulties in inspiring the students to make critical analyses of nursing procedures and routines as well as to learn by reflection in action and on-action. Accordingly, something must be done in order to improve the learning environment during the clinical part of nursing education.

\section{'Learning how to learn' methods}

Problem-based learning (PBL) is well established in health education (Alavi, 1995; Blackford and Street, 1999; Inouye and Flannely, 1998). This educational method has been used in various programs over recent decades, but in nursing education few experiences have been reported of using PBL in clinical education (Biley and Smith, 1998; De Villiers et al., 2004). Since this kind of learning encourages self-conducted, individualised learning and thereby also the students' own responsibility for learning, it should also support the personal and professional growth of the student. Using experiences from clinical practice, as a starting point when training abilities for problem solving and critical analysis, should greatly increase integration between theory and practice.

Another method of learning how to learn, which is illustrated in the literature, is guided reflection. This method has been found to open new ways of bridging the theory-practice gap, since it takes into consideration both cognitive and affective elements in the reflecting process (Cooke and Moyle, 2002). In accordance with guided reflection, PBL is also built on the ideas of supervised reflection, but is mainly focused on cognitive knowledge. A combination of guided reflection and PBL could facilitate affective, cognitive, and psychomotor learning during clinical education. 
PBL has been implemented in the theoretical part of the nursing education program at several universities in Sweden during the last few years. Yet, experience from PBL in clinical education and integration between theoretical and clinical parts of the curriculum is scarce. The aim of the study was to describe nursing students' and their preceptors' experiences of problem-based learning and a new model for clinical supervision in clinical education.

\section{Method}

\section{Participants}

\section{Students}

All the students $(n=45)$ in the second year of their 3 -year nursing program participated, including 7 men and 38 women. The participants' median age was 25 years (range 21-36). The course was directed to nursing in medical and surgical hospital care units and covered 15 weeks full-time studies. Students' experiences and background varied. About half the students had some working experience from health care, while the rest had no experience at all. It was the students' first clinical placement in the nursing program. All students had experience from PBL as an educational method from their preclinical studies which included self-directed learning and group seminars based on patient scenarios.

\section{Preceptors}

A total of 30 nurse preceptors and four head preceptors at medical, surgical and orthopaedic hospital units at four Swedish hospitals participated, all of whom were supervisors for the participating students.

\section{The project}

The objective of the developmental project was to improve nursing students' integrated learning during clinical education, ability to actively search for knowledge, reflect critically, and to improve the clinical learning environment. The key components of the project were: PBL as an educational method, guided reflection and a supervision model supporting the preceptors. Support was provided for preceptors including training in PBL, reflection and techniques for literature search for nursing research.

At the start of the clinical placement the students identified their individual goals related to the objectives of the curriculum. Learning on the unit was built on ideas of continuity, where it was possible to establish a trustful relationship between the student and the staff. Students had opportunities to visit reference units, if needed, to study and participate in specific nursing procedures and activities.

\section{Model for enhanced clinical supervision}

Each student was assigned to a nurse who acted as a personal preceptor for the student during the whole clinical placement covering 11 weeks. The nurse was responsible for the supervision and support of the student's self-directed learning. The nurse should support the student in the process of socialisation into the nursing role as well as in helping the student reflect upon events in daily work concerning patients, families and co-workers. The student's critical analysis of own values, attitudes and behaviour as well as of procedures and routines in nursing was to be highlighted. The personal preceptor was a registered nurse who had a 5 weeks (7.5 ECTS credits) preceptor course and had at least 2 years clinical experience as a nurse.

\section{Head preceptor}

The head preceptor was responsible for a group of students from different units and was supposed to work primarily with the whole group of students. She arranged, together with the clinical lecturer, weekly meetings with the students, all of which were planned, implemented and evaluated based on problems and questions from the clinical field. At these meetings experiences, such as caring procedures and interpersonal relations, were reflected upon and discussed from affective, cognitive and psychomotor perspectives. In this way, with the support of the clinical lecturer, the students as well as the head preceptor got the opportunity to deepen their discussions. Experience from practice could be illuminated and critically analysed by means of theoretical knowledge and then redefined and extended within practice. The head preceptor was also supposed to support the personal preceptor in her work with supervision and also, when necessary, be supportive of individual students, as, for example, in setting individual goals and learning outcomes. The head preceptor was a registered nurse with a Bachelor of Science in Nursing, at least 5 years clinical experience as a nurse with a good reputation, and experience of supervision for more than 2 years.

\section{Clinical lecturer}

The clinical lecturer, who had a joint appointment with the university and the hospital, and 
had a Masters degree in Nursing, collaborated closely with the personal preceptor, the head preceptor, the clinical senior lecturer and the university teachers. Besides the weekly meetings, the clinical lecturer together with the clinical senior lecturer, managed a network of nurses twice each term involving personal preceptors, head preceptors and university teachers. These networks aimed at improving the interaction between theory and practice, supporting progress in reflection and critical thinking, and utilising research findings in daily nursing care.

\section{Clinical senior lecturer}

The clinical senior lecturer, who had a PhD in nursing, had overarching responsibility for the quality of the clinical education program, by developing curricula and examinations, as well as for the co-operation between the theoretical part of the program and the clinical fields at a management level through regular meetings with managers.

\section{Implementation}

Every student was assigned to a personal preceptor and had access to a head preceptor and clinical lecturer. The units were offered reimbursement from the university of $4 \mathrm{~h}$ each week per student for clinical education by personal preceptors and $8 \mathrm{~h}$ for head preceptors.

During clinical education, theory and practice were integrated in a PBL context. To accomplish this, there were weekly small student group meetings. At the meetings specific themes in nursing care were focused, such as nutrition, elimination and acute pain. Students, clinical lecturers, head preceptors, and, when possible, personal preceptors, took part in the base group meetings.

To the bi-weekly meetings students were asked to bring patient scenarios from their units, which were used for integrating practice and theoretical knowledge. Students also met every other week to reflect on situations and events based on their field notes, based on significant experiences in their clinical learning. These meetings were also used to discuss the project and perceptions of PBL. Clinical lecturers also arranged clinical lectures or demonstrations by experienced nurses from the clinical field. Preceptors, head preceptors and clinical lecturers met regularly to evaluate and develop teaching strategies. During the project clinical lecturers together with clinical units initiated the building of networks for nurses from various units for specific clinical issues of concern, as, for example, nutrition, documentation and quality improvement.

\section{Data-collection}

The following measures were used to evaluate the project: Questionnaires to all students $(n=45)$ and preceptors $(n=30)$ who were involved in the project to evaluate clinical studies, developed for this project and based on research on factors which support or impede nursing students clinical learning (Löfmark and Wikblad, 2001). The questions were reviewed and validated by a group of clinical lecturers. The questionnaire contained questions on students' and preceptors' knowledge of goals, content and accomplishment of clinical education and learning; expectations in terms of knowledge, organisation of how the goals of the curricula were to be met; attitudes to PBL and reflection, assignments, grading and students own responsibilities; the integration of theory and practice; cooperation between clinical units and the university; and the supervision model. Answers were given on a visual analogue scale as well as in free text. In this paper, the free text responses were used for the analysis. Interviews were also performed with the head preceptors $(n=4)$ based on an interview guide with open-ended questions.

Rigour of the data was aimed for by collecting data from both students and their clinical preceptors, to provide multiple perspectives on the project. By using both questionnaires and interviews, data could be validated. Also, the interviews were performed by a nurse who was independent from the researchers and not involved in the project, to avoid bias.

Data-collection was performed at the end of the project. Questionnaires were distributed by the lecturer who was managing the project, and interviews were performed by a student in the Master program. Participation was voluntary, and all students and preceptors who took part in the project accepted to answer the questions. They were informed that data were confidential and that individual responses would not be possible to trace in the presentation of findings. No formal ethical approval was sought as this was part of an educational development project, which does not fall under the Swedish legislation for research ethics. All managers at the hospital units agreed to participate in the project.

\section{Data analysis}

Data from interviews and open-ended questions in the questionnaire were analysed using content analysis. 


\section{Results}

\section{Experiences of the supervision model}

Overall, students perceived the project positively, especially the relationship with their personal preceptor. Students felt that their personal preceptor trusted them and their responsibilities for care activities increased as time went on. Being able to take responsibility beyond what they had expected and being trusted by their preceptor was an important encouraging factor in learning, according to the students. Student also appreciated to be respected as students, which increased their self-esteem and self-confidence. The role of the head preceptor was not clear to all students and therefore, not used to the intended extent.

Some student comments were:

"I have had very good support and freedom when I wished."

"My preceptor has been good."

The opportunities to meet with other students in the small group for reflection were seen as very valuable. The use of field notes as the basis for reflection with their personal preceptor or clinical lecturer was also perceived by students as enhancing their learning. The students expressed that their opportunity to gain an overall picture of patient care was enhanced. The support from preceptors by deeper discussion and reflection on performance was stressed as well. Examples of comments from students were:

"I have had time set aside for reflection."

"Enormously important to get things off your chest."

"It has been good to talk about situations you have experienced."

"The small group meetings when my preceptor participated have been very rewarding, as we could continue the discussion later on at work on the unit."

The possibility to get designated time for student supervision was seen as very positive by the nurse preceptors. Preceptors appreciated that student supervision and the role of the preceptor was made visible. Opinions were expressed, such as:

"It is important that the organisation is in agreement with the need for designated time for supervision and not consider this as a burden on the unit."
"During the project there have been a lot of discussions on the unit about supervision and the link between theory and practice."

However, on some units personal preceptors found that there were few possibilities to set aside time for supervision, since the working situation was tough. This imposed an obstacle to preceptors' involvement in students' small group meetings. Moreover, some preceptors perceived students clinical assignments and examinations 'from school' as intruding on students ability to be active in patient care on the unit.

Statements by preceptors were, for example:

"The student is happy, but I, myself, have wished for more time for supervision before and after certain caring interventions."

"The opportunity to set aside time for reflection with the student has partly been dependent on the current workload at the unit.",

"Study assignments were often perceived by students as onerous and have taken time and effort from caring activities."

Some head preceptors found their role to be unclear, which was expressed in statements such as:

"It was a new function for me and for my unit and, therefore, I was uncertain how I should manage this role and avoid intruding on the work of the personal preceptors."

\section{Experiences of problem-based learning}

The students expressed that PBL promoted greater freedom but also greater responsibility. They appreciated taking greater responsibility for how they would reach the goal of the clinical studies. Students expressed how they developed the ability to be active and to gain knowledge independently, and to be able to handle situations when interacting with patients and their families. Some students described the importance of the base group. But there were also students who perceived PBL as impeding their clinical training. They wished that clinical studies were completely free from base group meetings and teaching assignments.

Students wished for more opportunities to influence their clinical education on the units.

Some comments from the students were:

"I have had good control of my learning needs and had the opportunity to take a great deal of responsibility for this during the second part of my clinical placement."

"It is my education and it is my responsibility." 
"I think problem-based learning is good, although it cannot always be applied. You get a 'why' and $a$ 'how' into your thinking and acting."'

"I have been able to express my views, but if it has been taken into consideration is another thing."

Factors seen as positive by the preceptors were their knowledge of PBL, the effect of reflection on learning, as well as to be able to offer students individual supervision. Preceptors perceived that they could affect student education in a different way from before.

"I like supervising, want to learn more about PBL and how to apply research to daily care together with my student."

The support for students to access nursing research during their clinical placement was not perceived by students as prioritised. Some preceptors agreed that they did not stimulate students to access nursing research and other sources of knowledge to the extent that they had wished. Some examples of statements from preceptors were:

"We don't have the time ourselves to read reports and being informed about nursing research."

"They (the students) are skilled at this themselves - we hardly have the time."

"It has not been needed. I had an independent student with high standards."

The students commented, for example:

"There was no time to search for current research. I have learnt about what I have come across."

\section{Discussion}

The aim of the project was to improve students' integrated learning during clinical training by using PBL as the educational method, supervised reflection, development of a supervision model, clinical education linked to base units, as well as support for nurse preceptors.

Overall, students perceived the project positively, in that they felt more freedom and responsibility in learning, which supports findings from other studies on PBL (Cooke and Moyle, 2002; De Villiers et al., 2004; Williams, 2004). Students' perceived that the regular meetings with other students for reflection and the relation with the preceptor enhanced their learning, which coheres with findings from previous research (Brysiewicz et al., 2002). Some students found PBL unfamiliar and believed it often took time from patient care and other tasks. Since theory and practice were integrated in base group sessions, students found there was a great deal of theoretical work during clinical training. This was unfamiliar at the beginning for students who expected they would only be dealing with 'practical care knowledge'.

The preceptors appreciated having designated time for supervision and felt that their teaching duties were made visible and more respected. Personal preceptors felt, in spite of preceptor training, some uncertainty over how PBL should be applied. Some head preceptors had problems finding their role and expressed uncertainty over how to act when relating to personal preceptors and students. It was sometimes hard for the units to set aside the agreed designated time for supervision. Nurses who participated in the project sometimes felt their involvement increased the workload of their colleagues. This shows the persistent problem with legitimising the educational function in clinical nursing. Some unit managers did not succeed to organise the work in such a way that preceptors could fulfil their supervising tasks.

Some students, as well as preceptors, expressed that theoretical content was intruding on the practical training. In spite of the objectives of the project, some participants expected that 'theory' would be dealt with in theoretical courses and pure 'practice' would be part of work-based training. This notion of theory and practice as two separated entities has strong rotes within nursing. As the academic growth within nursing is still in a developing stage, this is not surprising. This finding from our project shows the need for further discussions and collaboration between universities and clinical settings about good nursing education for the future needs in health care.

The possibility for reflection together with personal preceptors and, continually with the base group, was expressed as very positive by the students, in accordance with findings in previous studies (De Villiers et al., 2004; Williams, 2004). However, preceptors reported that they were not always able to meet students' need for reflection, because of lack of time, which has been reported as an obstructing factor for students learning in previous studies (Löfmark and Wikblad, 2001).

Both students and preceptors expressed the difficulty of applying research results, and of linking clinical studies to research, a finding that coheres with previous studies on nurses' perceptions of research use (Nilsson Kajermo et al., 1998). Both groups expressed that there was lack of time and a lack of possibility to search for and apply relevant nursing research. 


\section{Limitations of the study}

As the participants were involved in an educational development project, they could have been inclined to give positive responses to the questions. Free text responses from a questionnaire constituted part of the data, which produced text that was poor, compared to what would have been possible with interview-data.

\section{Conclusions}

The experience from the project showed that PBL and the model for clinical supervision were perceived, overall, in a positive way by students and their preceptors.

The link to research in clinical studies needs to be strengthened through the building of networks of nurses and researchers. Preceptors also need to develop their skills in nursing science, scientific methodology and specific nursing science within their area of clinical expertise. The use of reflection needs to be developed and applied to different situations in connection with training of preceptors. Further, collaboration between health care clinics and the university needs to be developed.

To be successful in implementing PBL in clinical education continuous information, training and support of students and preceptors is needed. Many nurse preceptors are unfamiliar with PBL and lack own experiences from this educational approach. The working process of PBL can challenge students to reflect over their learning with respect to a particular situation and how they can use this knowledge in similar care situations in the future. PBL can prepare students for their working life by engaging them in authentic situations during clinical training and by acquiring strategies for life-long learning in their professional careers.

\section{Acknowledgements}

The project has been made possible through funding from The Swedish Council for Higher Education and the commitment of students, clinical preceptors and teachers. Special thanks to Dr. Elsy Athlin who contributed in planning of the project, and the project-group of nurses and lecturers who engaged in the implementation of the project.

\section{References}

Alavi, C. (Ed.), 1995. Problem-based Learning in a Health Sciences Curriculum. Routledge, London.

Baker, C., 2000. Problem-based learning for nursing integrating lessons from other disciplines with nursing experiences. Journal of Professional Nursing 16 (5), 258-266.

Benner, P., 1984. From novice to expertExcellence and Power in Clinical Nursing Practice. Addison-Wesley Publishing Company, Menlo Park, California.

Biley, F.C., Smith, K., 1998. Exploring the potential of problembased learning in nurse education. Nurse Education Today 18, 353-361.

Blackford, J., Street, A., 1999. Problem-based learning: an educational strategy to support nurses working in a multicultural community. Nurse Education Today 19, 364-372.

Bowden, J., Marton, F., 1998. The university of learning. Beyond Quality and Competence in Higher Education. Kogan Page Ltd., London.

Brysiewicz, P., Cassimjee, R., Mclnerney, P., 2002. An exploratory survey of undergraduate nursing students' experiences of group work within a Problem-Based curriculum. Curatonis (November), 12-20.

Cooke, M., Moyle, K., 2002. Students' evaluation of problembased learning. Nurse Education Today 22, 330-339.

Craddock, E., 1993. Developing the facilitator role in the clinical area. Journal of Nursing Education 13, 217-224.

De Villiers, J.C., Joubert, A., Bester, C.J., 2004. Evaluation of clinical teaching and professional development in a problemand community-based nursing module. Curatonis (March), 82-93.

Estabrooks, C.A., 2003. Translating research into practice: implications for organizations and administrators. Canadian Journal of Nursing Research 35 (3), 53-68.

Fitzgerald, M., 1994. Theories of reflection for learning. In: Palmer, A., Burns, S., Bulman, C. (Eds.), Reflective Practice in Nursing, The Growth of the Professional Practitioner. Blackwell Scientific Publications, Oxford.

Grahn, G., 1987. Educational situations in clinical settings. A process analysis. Doctoral dissertations at Uppsala University. Uppsala Studies in Education, 27. Acta Universitatis Upsaliensis.

Inouye, J., Flannely, L., 1998. Inquiry-based learning as a teaching strategy for critical thinking. Clinical Nurse Specialist 12 (2), 67-72.

Kaviani, N., Stillwell, Y., 2000. An evaluative study of clinical preceptorship. Nurse Education Today 20 (3), 218-226.

Lee, P., 1997. What training do preceptors require? Journal of Clinical Nursing 6, 249-250.

Löfmark, A., Wikblad, K., 2001. Facilitating and obstructing factors for development of learning in clinical practice from a student perspective. Journal of Advanced Nursing 34 (1), 43-50.

Mallette, S., Loury, S., Engelke, M.K., Andrews, A., 2005. The integrative clinical preceptor model: a new method for teaching undergraduate community health nursing. Nurse Educator 30 (1), 21-26.

McCaugherty, D., 1991. The use of a teaching model to promote reflection and the experiential integration of theory and practice in first-year student nurses: an action research study. Journal of Advanced Nursing 16, 534-543.

Murphy, J.I., 2004. Using focused reflection and articulation to promote clinical reasoning: an evidence-based teaching strategy. Nursing Education Perspectives 25 (5), 226 231. 
Nilsson Kajermo, K., Nordström, G., Krusebrant, A., Björvell, H., 1998. Barriers to and facilitators of research utilization, as perceived by a group of registered nurses in Sweden. Journal of Advanced Nursing 27 (4), 798-807.

Öhrling, K., Hallberg, I.R., 2000. Student nurses' lived experience of preceptorship. Part 2 - the preceptor-preceptee relationship. International Journal of Nursing Studies 37, 25-26.

Schön, D.A., 1983. The reflective practitioner. Basic Books, New York.

Schön, D.A., 1987. Educating the Reflective Practitioner, Toward a New Design for Teaching and Learning in the Professions. Jossey-Bass Publishers, San Francisco.
Severinsson, E.I., 1998. Bridging the gap between theory and practice: a supervision program for nursing students. Journal of Advanced Nursing 27, 1269-1277.

Wallin, L., Boström, A.M., Wikblad, K., Ewald, U., 2003. Sustainability in changing clinical practice promotes evidence based nursing care. Journal of Advanced Nursing 41 (5), 509-518.

Williams, B., 2001. Developing critical reflection for professional practice through problem-based learning. Journal of Advanced Nursing 3 (1), 27-34.

Williams, B., 2004. Self direction in a problem-based learning program. Nurse Education Today 24, 277-285.

Available online at www.sciencedirect.com 